\title{
Handicrafts and Aesthetics of Qiang People's Silver Accessories*
}

\author{
Wanyu Zhang \\ Fashion and Design Art Institute \\ Sichuan Normal University \\ Chengdu, China
}

\author{
Muqie Refu \\ Fashion and Design Art Institute \\ Sichuan Normal University \\ Chengdu, China
}

\begin{abstract}
Qiang silver ornaments refract out Qiang people's faiths, customs, folk wisdom and cultural history and play an important role in Qiang people's lives. The techniques of Qiang silver ornament have formed unique ethnic characteristics with the change of history and different techniques are closely related with their patterns and meanings. Analyzing Qiang silver ornaments' techniques and their aesthetics features is not only an exploration of the essence of Qiang ethnic techniques, but also a deep understatement on Qiang culture. By a aesthetic discussion on the application of Qiang silver ornaments in daily life, this paper will make analysis on techniques and aesthetics of the typical skills of Qiang silver ornaments. The techniques of Qiang silver Ornaments symbolize the cultural identity of Qiang people. Study the techniques and aesthetic characteristics of Qiang silver ornaments will help us deeply understand the spirit of Qiang and better protect the culture of Qiang.
\end{abstract}

Keywords-Qiang; silver ornaments; techniques; aesthetics

\section{INTRODUCTION}

Qinag is one of the ancient ethnic groups in the west of China.During it's long history, the Qiang people, although have not developed their own unique character system, yet have endued memory and history of their ethnic with superior wisdom on their resplendent silver ornaments, which gives a full reflection of their ancient religious worship--Animism. The inspirations of ornaments' various shapes and patterns, derived from geography and religious legends and myths, are symbolic images and graphs.For thousands years, except for being the popular ornaments, they also have been given sorts of cultural meanings and religious affections, carrying the massive historical memories, value of life and sense of worth of Qiang people and being praised as the " materialized ethnic history and civilization history."

\section{THE DAILY APPLICATION OF QIANG SILVER ORNAMENTS}

Qiang silver ornaments, loading with distinctive personalities, consummate crafts, rigorous procedures and exquisite details, imply luckiness in it's patterns and sentiments in it's ingenuity. Qiang people homage white color and silver ornaments just fit to their color preferences. It's techniques and other aspects are influenced by history, art and philosophy.From Qiang people's daily ornaments to religious

*This paper is supported by laboratory project of Sichuan Norma University(SYJS2016037). sacrificial objects, silver ornaments have not only embodied the ethnic wisdom of Qiang people, but also influenced the development of ethnic art and culture, providing later generations with available reference to study Qiang culture and understand the spirit of Qiang people.

Silver bobs, earrings, ear pendants, collar isigninas, silver badges, silver bracelets, rings and so on are all the pleasant ornaments of Qiang women.And above most of these ornaments, agates, jades and corals and other gems are embedded.

Headdress: Hairpin is a headdress ancient women commonly used. Wen Tingyun once eulogized a lady in his poem: "The jade hairpin in her hair is as cool as the autumn water and the fine gauze next to her is as lithe as cyan mist". Qiang women maintain the habit of wearing hairpins up to now Patterns of the hairpins mainly take moire, animal, plant and so on as decorations and hairpins with moire patterns means luckiness and safety. Living at a high altitude, Qiang people are known as "the people on the cloud". They believe that the cloud is a revelation of gods, so they create a variety of patterns with the image of clouds. In addition, The headdress with Phoenix pendants is produced with filament, signifying the ancient Buyao (a kind of headdress with long pendants to restrict the width of a woman's step). When the pendants shake with the woman's walking, it looks like a picture that a Phoenix spreads it's wings to fly up. Moreover, the daily consumption of Sippen wine brewed with wheat and barley is a habit of Qiang people, and wheat pattern as well as barley pattern on the hairpins have recorded the memory of ancient of Qiang people.[1]

Earrings: "Melon rice" earrings are the ornaments young women wear more frequently, and larger earrings and ear circles are also in their fond lists. While middle-aged women wear silver-flake ear pendants with "old coin" style more.

Collar ornaments: Qiang people always inlay a a row of small pieces of silver plum blossom patterns on collars, sleeves and other parts of woman's clothes. Silver collar buckle symbolizes the pure love. It is said that when a gentleman falls love with a lady, he would insert rhododendrons in the lady's collar to show love.Thus then the silver collar buckle replace the legendary rhododendron and become a symbol of love.[2][3] 
Breast ornaments: The badge hanging in front of the chest, excepting for decorating for beauty, also expresses Qiang people's religious faith and worships. It has abundant exquisite chiseled patterns, covering flowers, nature and other topics. In the cloth of Jiaochang village in Mao county, the badge patterns show Qiang people's worship on the sun and the moon as well as the stars. Besides, bonnet is also set with several silver badges endued with auspicious characters on it's forehead edge.Among these badges, the middle one is always engraved with Bodhisattva or "Shou" character which stands for wishes of health in Chinese. And on both sides, the silver badges are separately engraved with terms like "Chang ming bai sui" (means longevity in Chinese) or "Fu gui ji xiang" (means wealth and luckiness in Chinese) or "Chang ming fu gui" (means longevity and wealth in Chinese) or "Rong hua fu gui" (means prosperity and wealth in Chinese) and so on. Rear to the bonnet, small silver bells are set as decorations, and when children shake their head, silver bells will jingle lively and smartly.

Ornaments on hands: Wearing silver bracelet is a custom evolving from the immemorial Qiang people's rattan wearing on the wrist.[1] Although the material has changed into silver, the style maintains the image of rattan. And at the same time, hollowing, sculpturing, engraving and other techniques are adopted and a lot of flowers, moires, plants and other patterns are used as decorations.

Waist ornaments: Qiang men are go in for fire sickle, knife and silver cigarette box as their waist ornaments while omen prefer silver needle box. When the Qiang go out, they will carry a silver Bodhisattva with them. When there is a need, they will take it out to pray to god for peace and luckiness.

The habits of wearing silver ornaments are vary from different Qiang settlements. In Oxtail village of Mao county, the shapes of silver badge are mostly geometrically shaped, such as square, round and diamond-shape. People carve animals, plants and other patterns out, and then wrap with petals or stems around to pray for God's bless from evil spirits. While in Chibusu district of Mao County, women prefer to embellish their clothes with silver badges and buckles. In addition, women in Puxi of Li County love to wear silver ornaments and earrings and women in Weizhou and Yanmen of Wenchua like to wear hairpins. [4][5]

Most of Qiang silver ornaments convey the main information of blessing, evil-avoiding, and longevity. Exquisite techniques are used to deal with vivid patterns rigorously, which reflects Qiang people's living customs and ethnic wisdom, delivering the history and culture of Qiang.

\section{THE TECHNIQUES OF QIANG SILVER TECHNIQUES AND THEIR AESTHETIC CHARACTERISTICS}

Different patterns and shapes of silver ornaments are modeled with different techniques.The main material of traditional Qiang silver ornaments is silver and basic tools are rosin board, silk plate, moulage, crucible, hammer, copper pot, leather tiger, sorts of pliers, chisels, iron anvils and so on.And the processes mainly includes casting, hammering, molding, carving, hollowing, filament, besetting, welding, pickling ect.

\section{A. The Uninhibited Beauty of Hammering}

Qiang silver ornaments are made with perfect techniques. A majority of them need many processes such as hammering, chiseling, filament and other complex procedures to complete. Take hammering as an example, it is only a tiny part of Qiang silver craft culture, but it represents the concentrated crystallization of Qiang silver craft's traditional and historical features, making Qiang silver techniques glow with a bright humanistic light. When hammering, people need a rosin board to fix a silver plate whose shape and patterns are pre-designed. Hammering after cooling and then heating, the silver plate will separate from the rosin board. As shown in "Fig. 1 to Fig.3", the preparation of sheeting means removing the scraps from left materials and then hammering them into a suitable sheet. After that, tailor the hammered sheet and sandwich it between the tin mold and hammer it next, repeating until the pattern in the mold is gradually clear on the blank, which is called billeting. And billet repairing means putting substrate on the blank, clearing the outline of the pattern with chisel again and again until the height of pattern is appropriate.
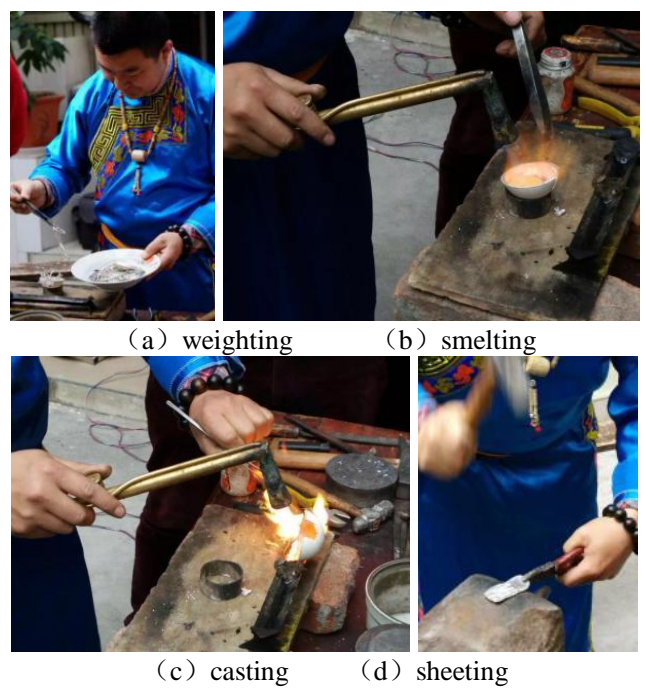

Fig. 1. Sheeting.

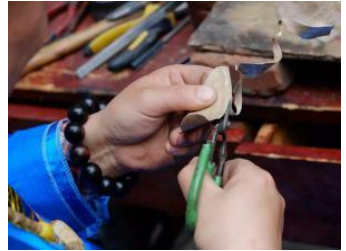

(a) tailoring

Fig. 2. Making embryos.

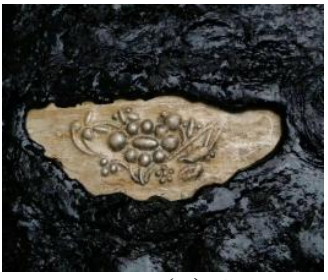

(a) fixing

Fig. 3. Finishing.

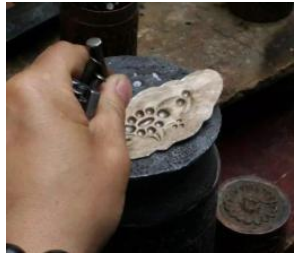

(b) hammering

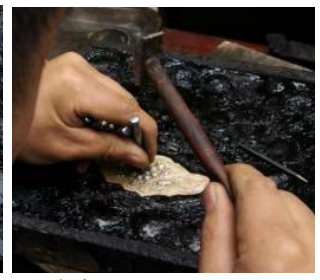

(b) carve 
Among the performance techniques of hammering, high convex hammer and raised hammer are the common forms. High convex hammer can express sense of three-dimensional easily with it's deeper plane hammer to highlight the bottom of the pattern.The high convex hammer in "Fig.4" can show a strong sense of level. It's highly raised petals contrast with the dot-dense decorative patterns on it's the edge in the texture, emphasizing the spatial level and deep layout of silver ornaments, so that the visual effects of interspersed and hierarchical can emerge on the surface of the silver ornaments.Relief hammer is easy to present rich levels and dynamic patterns, thus the relationship between the picture and background is particularly distinctive.In picture $4 \mathrm{~b}$, the hammered dense dots is the background, and the fine texture makes the pattern more obvious. Hammering in this way handles illusion and reality properly.And The dignified and stable decorative body presents a high aesthetic value.

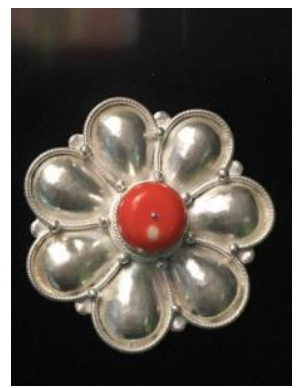

(a) High convex hammer

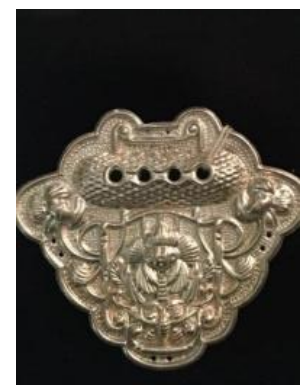

(b) Relief hammer
Fig. 4. The Hammered silver ornaments.

Among Chinese traditional techniques, "Come from nature but beyond nature" is the best state of an art. Handicrafts, distinctively differing from batched and standardized mechanized production, reflect the feature of unreplicable of utensils. In Qiang silver ornaments, a craftsman express his ethnic philosophy through his personal feelings and artistic creation. Those feelings originated from Natural Religion have been transformed and sublimated. The purity and simplicity of silver ornaments contains naturality, sociality and regionality, and handcraft will make silver ornaments more temperate and bear a richer emotional tone.

\section{B. The Perfect Beauty of Chiseling}

Chiseling happens when hammering has been done, the craftsman has to choose the type of a chisel to step into careful trimming and pattern making. A lot of patterns in Qiang silverware are carved with a chisel by a silversmith to create more various and clearer patterns based on the pattern's outline suppressed in tin mold. There are also silversmiths chisel on the sheet directly, without drafting or moulding, which requires a quiet excellent painting capability and sculptural skills, planing in the heart and skilled in the heart.

"Chiseling, engraving, hollowing" and other carving processes form a integrated model of diverse, full and threedimensional for silver ornaments in their artistic forms. [7] Embossed chiseling and spatial extensible hollowing expand it's morphological feature and transform the semantics of it's style. As far as the visual performance, "chiseling, engraving, hollowing" are equal to the void and blank of Chinese painting.
In Chinese aesthetic ideology, "The actual situation is raw life" is the core part, it is embodied in the chiseling process of Qiang silver ornaments. What's more, "See infinity in the finite ", a figure of performance that using chiseling to express sense of level and creates infinite imaginary space with in finite realistic space, has enhanced the physical impression of silver ornament and made it convey a kind of real affection in it's real touch of the texture, arousing positive emotional echo of people. The silver hairpin in "Fig. 5" has embossed form and pattern adding the spatial sense of level on it's cambered surface and the dynamic language on the hairpin of twisted texture. The manual dents of chiseling form a visual contrast with smooth texture of the hairpin, forming different aesthetic sensations visually.And Qiang people's tenacity and softness in their character, are also perfectly showed in the toughness and extension of the hairpin's lines, which combine the sentiments of rigidness and tenderness. "Fig. 6" shows a silver badge, which is chiseled from single-layer rectangular silver sheet and whose layout reflects the style languages of symmetry, balance as well as centrality, highlights the auspicious patterns of phoenix, fish, claw flower and ect in shallow cameo and chiseling, and reflects people 's emotional and aesthetic ideology. The silver badge uses a hammer to produce circular, triangular, square, diamond and other background patterns, then use a chisel to perform the body pattern, coordinating the illusion and reality and making it vivid and natural. Silver badges are connected in serial by silver chains which hang bells in their bottoms, smoothing the entire style and balancing the density.

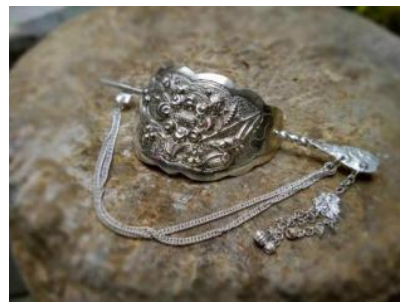

Fig. 5. A silver bob.

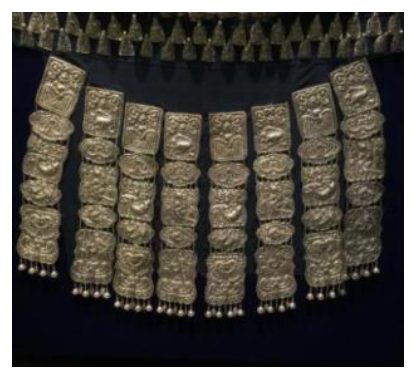

Fig. 6. A silver badge.

As a result of the fine procedures of chiseling, silver ornaments can show rich modeling language in space, which displays the artistic quality of design. Chiseling not only reveal the art form of silver ornaments, but also convey the composite connotation of Qiang culture such as ethnic belief, historical transition and aesthetic appeal. 


\section{The Ingenious Beauty of Filament}

Filament, also known as Gold refining and silk, means refining a piece of silver into a filament and then pile it up.The main approaches are pinching, filling, gathering, welding, heaping, basing, weaving, plaiting, decorating and so on.Twisted the original filament forwardly or reversely, and then pinch it into a variety of shapes and weld it onto a thin silver slice as a part of style after having flat the filaments into oblate flake. Among Qiang silver ornaments, filament is used to shape the outline.Pinching the filament into all kinds of patterns and welding them on the silver slice to create raised shallow relief line is a form of subtle and elegant, having a strong sense of decoration. The traditional filament and welding are always associated with enamel and Diancui(a decorative process means pasting the feathers of kingfisher on an ornament), which is praised in a folk idiom "Refine the gold into a filament, plait the filament with skilled hand and embellish it with jade and feather of kingfisher is one of the most wonderful techniques in the world".In the Qiang silver techniques, the filament is simplified.

There are few inlays in Qiang silk ornaments, but more winding, plaiting and welding with original filaments.Large pieces of silver ornaments like crown mainly adopt chiseling or unite the wiring.Filament's feature of delicate and smart suits for small items more such as earrings, pendants, headdress and so on better, because it saves materials and can describe details easier, and also has a wider space to perform creatively. If combined with hammering and chiseling or other techniques, it will be easier to compose a visual experience of virtue-real comparison and complexity-simple orderly ranging.

There is no lack of inspirations from nature in patterns and styles of filament process.Silver ornaments in "Fig. 7" mostly come from flowers, animals and plants in natural world. Lao Tzu mentioned in his "Tao Te Ching" that "Man models himself after Earth, Earth models itself after Heaven, Heaven models itself after Tao, Tao models itself after its nature";and Chuang Tzu also pointed out that "The nature lives with me in symbiosis, and everything is with me as a whole".Both of them are are the ideological representatives in aesthetic philosophy of our country, whose ideology that human nature is in highly harmony with nature is unified with Qiang animistic viewpoint. [8]
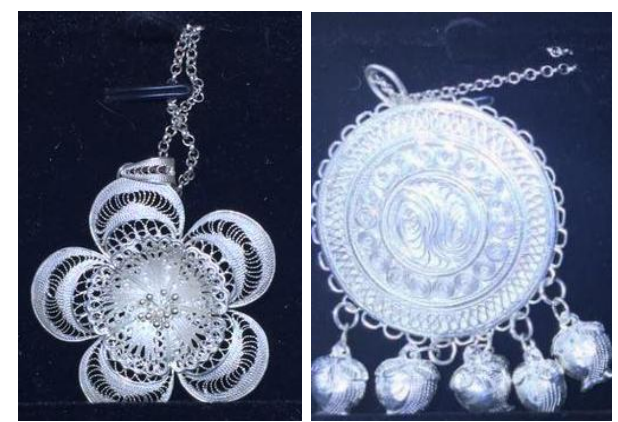

Fig. 7. Silver filament jewelry.

\section{CONCLUSION}

Qiang has many tribes. Although their accents and customs are different between a short distance, the silver ornaments show their same cultural identity. Silver ornaments convey the cultural foundation of the Qiang people, thus the interpretation of Qiang silver is an important way to understand Qian culture. Those silver ornaments that contain the cultural genes of Qiang people, are changing and evolving in the influence of modern civilization, being a graphic ethnic history and developmental history. [9][10] When it comes to the protection of Qiang culture, more attentions are focused on it's costumes or other aspects, leading the concerns on it's silver ornaments are relatively scarce. Compared with researches about silver on other minorities in Sichuan such as Tibetan and $\mathrm{Yi}$, the researches on Qiang silver ornaments are still far from enough currently. From the perspective of ethnic techniques to observe those of Qiang, we need carry out further researches and more extensive field investigations. By protecting Qiang culture, we are heading for leading more and more people to pay attention to Qiang silver ornaments.

\section{REFERENCES}

[1] Z. Yan.Inheritance and innovation:a study on the application of the traditional silver elements of Qiang in China jewelry.Journal of art.vol.3, 2015, pp. 91-92.

[2] D. Honglie.On relics of totem worship of the Qiang people.Guizhou ethnic studies, vol.5, 2015, pp.85-89.

[3] Z. Yuhua.The ethnic memory of the Qiang:a study of myths and legends of Qiang[J].Cultural heritage, vol.6, 2013, pp.82-88.

[4] R. Jianhua.A study of aesthetic consciousness in Qiang's folk culture.Art observation, vol.2, 2015, pp.126.

[5] Z. Jianshi.The relationship between traditional silverware craft and ethnic groups in southwest China[J].Journal of southwest university for nationalities(humanities and social science), vol.2, 2011, pp.46-49.

[6] C. Yan.Cultural interpretation of the goddess in myth of Qiang.Studies of ethnic literature, vol.6, 2014, pp.109-116.

[7] C. Xuemin.The art of chisel engraving in silver handcraft.Art observation.vol.9, 2013, pp.112.

[8] M. Cong.From heart to art: oriental aesthetics and aesthetic innovation of intangible heritage handicraft.Art panorama, vol.7, 2016, pp.94-95.

[9] Z. Rui.Literature review on the Qiang nationality in Japan with in recent 30 years:focusing on culture anthropology.Guizhou ethnic studies, vol.5, 2014, pp.77-80.

[10] Z. Wei.Cultural reconstruction and innovation in the change and presentation of the handicraft of Qiang.Packaging engineering, vol.1, 2015, pp.129-132. 